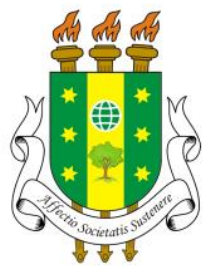

\section{A ORIENTACCÃO HOMOSSEXUAL E AS INVESTIGAC̄õES ACERCA DA EXISTÊNCIA DE COMPONENTES BIOLÓGICOS E GENÉTICOS DETERMINANTES}

\section{RESUMO}

A orientação homossexual masculina e a feminina tem substancial prevalência em humanos e pode ser explicada por componentes de vários níveis: biológico, genético, psicológico e sociocultural. No entanto, as evidências biológicas e genéticas têm sido as principais hipóteses testadas em pesquisas científicas no mundo. Este artigo teve como objetivo revisar os estudos de investigação acerca da existência de evidências biológicas e genéticas que determinam a orientação homossexual. Foi realizada uma revisão narrativa da literatura, utilizando as bases de dados MedLine/PubMed e Google acadêmico. Buscaram-se artigos científicos e livros nos idiomas português e inglês, utilizando-se os descritores: orientação sexual, comportamento sexual, homossexualidade, biologia do desenvolvimento, ordem de nascimento e genética. Foram selecionados trabalhos dos últimos 22 anos. Foram encontradas cinco principais teorias em torno dos componentes biológicos: (1) ordem de nascimento fraternal; (2) androgenização cerebral e a relação digital 2D:4D; (3) ativação cerebral por feromônios; e (4) hereditariedade epigenética; e quatro teorias acerca dos componentes genéticos: (1) polimorfismo genético; (2) padrão de herança ligada ao cromossomo X; (3) gêmeos univitelinos; e (4) seleção sexual antagônica. Conclui-se que foram muitas as evidências científicas encontradas ao longo do tempo para explicar alguns dos componentes biológicos e genéticos da homossexualidade, principalmente em indivíduos do sexo masculino. No entanto, ainda hoje, não há uma explicação definitiva sobre quais seriam os componentes determinantes da orientação homossexual.

PALAVRAS-CHAVE: Orientação Sexual; Comportamento Sexual; Homossexualidade; Biologia do Desenvolvimento; Genética.

\section{THE HOMOSEXUAL ORIENTATION AND INVESTIGATIONS ABOUT THE EXISTENCE OF COMPONENTS BIOLOGICAL AND GENETICS DETERMINANTS}

\section{ABSTRACT}

The male and female homosexual orientation has substantial prevalence in humans and can be explained by determinants of various levels: biological, genetic, psychological, social and cultural. However, the biological and genetic evidence have been the main hypotheses tested in scientific research in the world. This article aims to review research studies about the existence of genetic and biological evidence that determine homosexual orientation. Was conducted a review of the literature, using the database MedLine/PubMed and Google scholar. The papers and books were searched in Portuguese and English, using the following keywords: sexual orientation, sexual behavior, homosexuality, developmental Biology and genetics. Was selected papers of the last 22 years. Were found five main theories about the biological components: (1) fraternal birth order, (2) brain androgenization and 2D:4D ratio; (3) brain activation by pheromones; and (4) epigenetic inheritance; and four theories about the genetic components: (1) genetic polymorphism; (2) pattern of X-linked inheritance; (3) monozygotic twins; and (4) sexual antagonistic selection. Concluded that there were many scientific evidence found over time to explain some of biological and genetic components of homosexuality, especially in males. However, today, there is no definitive explanation about what are the determinants of homosexual orientation components.

KEYWORDS: Sexual behavior; Homosexuality; Developmental biology; Genetic.
Scire Salutis, Aquidabã, v.3, n.1, Out, Nov, Dez 2012, Jan, Fev, Mar 2013.

\section{ISSN 2236-9600}

\section{SECTION: Articles}

TOPIC: Genética

\section{Everton Fernando Alves}

Universidade Estadual de Maringá, Brasil http://lattes.cnpq.br/3222964702763728 evertonando@hotmail.com

\section{Luiza Tamie Tsuneto}

Universidade Estadual de Maringá, Brasil http://lattes.cnpq.br/0159850471384452 Ittsuneto@uem.br

Received: 26/10/2012

Approved: $20 / 02 / 2013$

Reviewed anonymously in the process of blind peer.

\section{Referencing this:}

ALVES, E. F.; TSUNETO, L. T.. A orientação homossexual e as investigações acerca da existência de componentes biológicos e genéticos determinantes. Scire Salutis, Aquidabã, v.3, n.1, p.62-78, 2013. DOI: http://dx.doi.org/10.6008/ESS2236$\underline{9600.2013 .001 .0006}$ 


\section{INTRODUÇÃO}

O relacionamento entre pessoas do mesmo sexo sempre existiu em todas as culturas, desde as sociedades primitivas. Tal condição foi interpretada, admitida e explicada de diferentes formas ao longo do tempo. Porém, a partir do século XIX a medicina definiu a homossexualidade como uma doença fisiológica, e no início do século $\mathrm{XX}$ a teoria psicológica de Freud foi a primeira a ganhar visibilidade com uma visão que considerou tal fenômeno como um desvio no desenvolvimento da sexualidade (PALMA, LEVANDOWSKI, 2008).

Em razão disto, o termo utilizado inicialmente, 'homossexualismo', serviu para retratar uma anormalidade, em função do sufixo ISMO, com uma conotação negativa de doença (PALMA, LEVANDOWSKI, 2008). Em 1948, a homossexualidade foi enquadrada como uma psicopatologia na $6^{\underline{a}}$ revisão da Classificação Internacional de Doenças (CID), na categoria Personalidade Patológica.

Com o advento dos estudos de caráter biocêntrico, inicialmente por meio do determinismo biológico, a visão sobre a homossexualidade foi sendo ampliada e revista (ROSARIO, 2002; MURPHY, 2000). Em 1973, a Associação Psiquiátrica Americana considerou que a homossexualidade não era uma patologia. Em 1975, foi a vez da Associação Americana de Psicologia (APA) retirá-la do rol de doenças (MATIAS, 2007). No Brasil, apenas na década de 80 o Conselho Federal de Medicina deixou de considerar a homossexualidade como uma categoria de desvios e transtornos sexuais.

Atualmente, a homossexualidade, também conhecida como orientação homossexual, é um dos quatro componentes da sexualidade humana. Caracteriza-se como uma duradoura atração emocional, romântica, sexual ou afetiva para com indivíduos do mesmo gênero (AMERICAN PSYCHOLOGICAL ASSOCIATION, 2008). O termo 'opção sexual' não deve ser usado, pois remete à ideia errônea da escolha de um indivíduo em ser homossexual, no entanto já se sabe que a orientação sexual é complexa e que sobre ela agem fatores genéticos, biológicos, psicológicos e socioculturais (DESSUNTI et al., 2008).

Para compreender a orientação homossexual como algo inerente à natureza humana, alguns pesquisadores têm buscado identificar as causas das diferentes orientações sexuais também em outras espécies. A bióloga americana Joan Roughgarden, professora da Universidade de Stanford, publicou um trabalho em que analisa cerca de 300 casos de comportamento homossexual entre as espécies humana e animal. Para a autora, a orientação homossexual é um traço natural que mantém indivíduos unidos através do contato (ROUGHGARDEN, 2004).

Em virtude da impossibilidade de se estudar por completo todos os componentes da homossexualidade, optaram-se pelas discussões sobre as influências biológicas e genéticas. Assim sendo, o presente trabalho tem por objetivo revisar os estudos de investigação acerca da existência de evidências biológicas e genéticas que determinam a orientação homossexual. 
Assim sendo, serão abordadas ao longo do texto algumas teorias científicas em torno dos componentes biológicos (ordem de nascimento fraternal, androgenização cerebral e a relação digital 2D:4D, ativação cerebral por feromônios e hereditariedade epigenética) e genéticos (polimorfismo genético, padrão de herança ligada ao cromossomo $\mathrm{X}$, gêmeos univitelinos e seleção sexual antagônica).

\section{DISCUSSÕES TEÓRICAS}

\section{Componentes Biológicos: Ordem de Nascimento Fraternal}

Essa é uma teoria de base biológica que sugere que efeitos maternos podem contribuir para o fenótipo homossexual. Segundo esta teoria, há uma curiosa relação entre a ordem de nascimento dos filhos e a incidência da orientação homossexual masculina, e vários estudos têm apoiado esta teoria desde a década de 90 (BAILEY et al., 2000; CAMPERIO-CIANI et al., 2004; KENDLER et al., 2000; HAMER et al., 1993; LEVAY, 1991).

A hipótese é a de que quanto mais irmãos mais velhos se têm, maior a chance de que o último menino a nascer possua orientação homossexual, como observado originalmente em 1996 por Blanchard e Bogaert em uma amostra de 877 homens heterossexuais e homossexuais canadenses (BLANCHARD, BOGAERT, 1996). De acordo com a teoria, a explicação para este fato se encontra na resposta imune da mãe a antígenos masculinos desenvolvida ao longo de sucessivas gestações de meninos.

Em 1997, um estudo de revisão realizado no Canadá demonstrou que essa progressiva imunização de algumas mães estaria relacionada aos antígenos de histocompatibilidade menor ligados ao cromossomo $\mathrm{Y}$ (antígenos $\mathrm{H}-\mathrm{Y}$ ) por cada um dos sucessivos fetos masculinos, bem como aos efeitos aumentados dos anticorpos anti-H-Y que passariam através da placenta e afetariam a diferenciação sexual do cérebro em cada um dos sucessivos fetos masculinos (BLANCHARD, KLASSEN, 1997).

Como os fetos femininos não produzem antígenos H-Y, eles não desencadeariam a reação imunitária. Esta hipótese apoia-se parcialmente sobre o argumento de que o sistema imunitário de uma mulher parece ser o mais capaz de "relembrar" o número de gestações prévias masculinas (mas não femininas) e então produzir uma alteração progressiva da sua resposta ao feto seguinte (BLANCHARD, KLASSEN, 1997). Diversas amostras de investigadores independentes tem apoiado essa teoria em diferentes épocas e países (CAMPERIO-CIANI et al., 2004; BLANCHARD, BOGAERT, 1996; BLANCHARD, BOGAERT, 1997; BLANCHARD, ELLIS, 2001; BOGAERT, 2003; GREEN, 2000).

Em 2001, um estudo publicado na Inglaterra analisou por meio de questionários 3.229 sujeitos (homens e mulheres adultos) provenientes dos Estados Unidos e do Canadá e confirmou, 
através da descoberta de que os homens homossexuais com irmãos mais velhos são substancialmente menos pesados no nascimento do que os heterossexuais com irmãos mais velhos, a hipótese de que o efeito da ordem de nascimento fraternal opera sobre o meio pré-natal (BLANCHARD, 2001; BLANCHARD, ELLIS, 2001). Além disso, uma pesquisa de meta-análise realizada no ano de 2000 demonstrou que o efeito da ordem de nascimento só é exercido sobre os indivíduos destros, além de estar também associado à surdez (LALUMIÈRE et al., 2000). No entanto, em 2004, um estudo de meta-análise realizado no Canadá afirmou que para a orientação homossexual em mulheres não existem evidências relacionadas à ordem de nascimento fraternal (BLANCHARD, 2004).

Para tanto, esse estudo utilizou dados de 14 amostras representativas de 10.143 indivíduos do sexo masculino provenientes dos Estados Unidos, Canadá e Reino Unido. Para o autor do estudo, a homossexualidade em indivíduos do gênero masculino pode ser prevista quando há maior número de irmãos mais velhos, mas não pelo maior número de irmãs mais velhas, irmãos mais novos, ou irmãs mais novas (BLANCHARD, 2004). A relação entre o número de irmãos mais velhos e a orientação sexual foi restrita apenas aos homens. O estudo citado sugeriu que entre 15 e $30 \%$ dos homossexuais podem atribuir a sua homossexualidade ao efeito de ordem de nascimento (BLANCHARD, 2004).

Em 2006, uma pesquisa realizada no Canadá também sugeriu que a orientação homossexual de um indivíduo é determinada mais pelas condições imunológicas do ambiente uterino durante a formação fetal que por fatores ambientais externos (BOGAERT, 2006). Nesse estudo, foram analisados quatro grupos de homens canadenses, heterossexuais e homossexuais, num total de 944 sujeitos, investigando o total de irmãos e irmãs de cada um, se os irmãos viviam juntos e se eram irmãos consanguíneos ou adotados. Para o autor, as condições químicas intrauterinas estão marcadas pelo número de irmãos mais velhos gerados anteriormente pela mãe, os quais predispõem o útero para que desenvolva uma maior quantidade de anticorpos contra as proteínas especificamente masculinas nas próximas gestações. Pesquisa realizada anteriormente no Canadá explicou que a influência sobre a tendência homossexual aumenta quando a mãe teve previamente três ou quatro filhos mais velhos (BLANCHARD, BOGAERT, 1997). Para os autores dessa pesquisa, estima-se que cada irmão mais velho aumente a chance do próximo ser homossexual em até $50 \%$.

O estudo aponta ainda uma relação entre o número de irmãos mais velhos e a homossexualidade numa proporção maior nos casos de filhos que têm a mesma mãe (BLANCHARD, BOGAERT, 1997). Dessa proporção, os autores deduzem que a orientação homossexual masculina tem uma origem pré-natal e que a memória biológica da mãe é uma causa determinante, já que existe só quando todos são filhos de uma mesma mãe.

O efeito da ordem de nascimento sobre a orientação homossexual masculina já havia sido notado antes, mas o estudo realizado por Anthony Bogaert em 2006 foi o primeiro projetado para excluir possíveis explicações socioambientais (BLANCHARD, BOGAERT, 1997; BOGAERT, 
2006). Para o autor, somente foi possível concluir que o efeito é biológico ao comparar os dados de homens com irmãos consanguíneos e os que têm irmãos de criação (BOGAERT, 2006).

\section{Componentes Biológicos: Androgenização Cerebral e a Relação Digital (2D:4D)}

Existem evidências de que homossexuais masculinos são expostos a altos níveis de testosterona na fase pré-natal e esse hormônio pode ter efeitos prejudiciais sobre o sistema imunológico e cerebral (ROBINSON, MANNING, 2000; MANNING, ROBINSON, 2003). Acreditase que os genes da família Homeobox ou Hox controlam a formação dos dedos das mãos e dos testículos masculinos. Assim, a possibilidade de associação entre o comprimento dos dedos e a exposição intrauterina à testosterona levou originalmente, em 1998, os pesquisadores canadenses Manning e colaboradores a sugerirem que a diferença entre o dedo indicador (2D) e o dedo anelar (4D) é estabelecida ainda no útero e parece não ser afetada pela puberdade (MANNING et al., 1998).

Essa teoria, que analisa o comprimento relativo do dedo indicador e anelar, é conhecida como Relação Digital (RD=2D:4D) (MANNING, ROBINSON, 2003). Para Manning e colaboradores, caso o dedo indicador seja menor que o dedo anelar ( $2 \mathrm{D}<4 \mathrm{D})$, a chance de um indivíduo ser homossexual é aumentada devido a maior exposição à testosterona durante a vida intrauterina (MANNING et al., 1998). A hipótese diz ainda que a orientação homossexual masculina resulta de um cérebro sobremasculinizado, ou seja, os homens homossexuais são hiper-androgenizados (ROBINSON, MANNING, 2000).

Em 2000, uma pesquisa realizada na Califórnia analisou as mãos de 720 pessoas, chegando a uma relação estatística entre o comprimento dos dedos e a orientação sexual do indivíduo (WILLIAMS et al., 2000). Nas mulheres lésbicas, havia diferença de comprimento entre o 2D e o 4D, isto é, suas mãos assemelhavam-se a uma mão masculina. Nos homens, por sua vez, os autores não encontraram diferença significativa entre o 2D e o 4D em homens heterossexuais e homossexuais. A relação estabelecida aplicou-se somente no caso de homens que tinham irmãos mais velhos, pois, geralmente, o primogênito tem o mesmo comprimento entre os dedos quer seja homossexual ou heterossexual (WILLIAMS et al., 2000).

Entretanto, em 2003, um estudo desenvolvido no Reino Unido analisou precisamente a relação contrária (MANNING, ROBINSON, 2003). Focou-se em homens homossexuais que tinham a diferença de comprimento dos dedos mais semelhante à feminina, o que levou a crer que tanto a exposição a níveis muito baixos como a níveis muito altos de testosterona no útero leva à orientação homossexual. Os autores sugerem, portanto, que é possível que existam dois fenótipos distintos de homossexuais masculinos. 


\section{Componentes Biológicos: Ativação Cerebral por Feromônios}

A teoria da associação entre a orientação homossexual e a ativação cerebral por feromônios também está no foco de pesquisas recentes. Em 2005, uma pesquisa realizada na Suécia apresentou fortes evidências de que seres humanos são capazes de produzir e detectar feromônios, isto é, substâncias químicas que atraem parceiros sexuais pelo olfato e que são empregadas por várias espécies animais (SAVIC et al., 2005). Foram duas as substâncias usadas no estudo: um derivado da testosterona produzido no suor dos homens e um composto similar ao estrogênio encontrado na urina das mulheres.

Para tanto, os pesquisadores suecos analisaram 36 indivíduos, divididos em três grupos (homens homossexuais, homens heterossexuais e mulheres heterossexuais) (SAVIC et al., 2005). Os autores da pesquisa observaram que nos cérebros de homossexuais do sexo masculino, mais especificamente na área pré-optica que abriga conglomerados neurais (núcleo hipotalâmico intersticial), há um aparente dimorfismo sexual cuja região do hipotálamo é ativada em resposta a derivados da testosterona, com propriedades similares às dos feromônios. Esses resultados se assemelham aos apresentados originalmente por Simon LeVay em 1991 nos Estados Unidos o que demonstrou, através de análise em tecido post mortem, que existem alguns núcleos sexuais dimórficos, como o núcleo intersticial do hipotálamo anterior 3 (INAH-3), diferente entre homens heterossexuais e mulheres lésbicas ou homens gays. Constatou-se que alguns desses dimorfismos sexuais no cérebro aparecem apenas depois dos primeiros anos de vida e outros, apenas na vida adulta (LEVAY, 1991).

No entanto, os autores suecos ressaltam que é impossível afirmar se suas observações refletem uma causa ou um efeito da homossexualidade, ou seja, não se sabe se é a orientação sexual que faz o cérebro de uma pessoa reagir dessa maneira, ou se as pessoas já têm o cérebro desenhado previamente para reagir desse modo às substâncias químicas masculinas e femininas (SAVIC et al., 2005).

\section{Componentes Biológicos: Hereditariedade Epigenética}

Epigenética é o campo da biologia que estuda as interações causais entre genes e seus produtos, os quais são responsáveis pela produção de fenótipos (SLATKIN, 2009). Em outras palavras, a epigenética se caracteriza pela alteração herdável na expressão gênica, sem que haja mudança na sequência primária de DNA (WOLFFE e GUSCHIN, 2000). Acredita-se que as interações entre genes e componentes ambientais podem modificar um traço ou uma predisposição genética (SLATKIN, 2009).

Em 2006, por exemplo, um estudo norte-americano mostrou ligação entre a constituição genética da mãe e a orientação homossexual dos filhos (BOCKLANDT, 2006). Segundo a pesquisa, as mulheres têm dois cromossomos $X$, um dos quais é desativado. A inativação de um 
dos cromossomos $\mathrm{X}$ ocorre aleatoriamente em todo embrião, resultando em células agrupadas em forma de mosaicos em relação ao cromossomo que está ativado. Em alguns casos, porém, observa-se que esta mudança pode ocorrer de uma maneira não aleatória. Para o autor, em mães de homens homossexuais, o número de mulheres com tendência à inativação do cromossomo $\mathrm{X}$ é significativamente maior do que em mães sem filhos gays. Treze por cento das mães com um filho gay, e $23 \%$ das mães com dois filhos gays mostraram forte tendência, se comparadas aos $4 \%$ das mães sem filhos gays(BOCKLANDT, 2006).

Em 2012, em entrevista dada pelo pesquisador sueco Urban Friberg, o fato de homossexuais produzirem menos prole do que heterossexuais indica uma possível variação genética negativa; por outro lado, dificilmente essa variação não seria removida ao longo das gerações (FRIBERG, 2012). Ainda segundo o pesquisador, a pergunta que intriga os cientistas evolutivos é: como a homossexualidade pode existir em uma frequência tão alta a despeito do processo de seleção natural?

A fim de responder a essa indagação, um estudo recente realizado nos Estados Unidos sugeriu que a orientação homossexual não está na genética propriamente dita, mas sim na epigenética, isto é, em componentes biológicos conhecidos como marcadores epigenéticos (epimarcas), que são transmitidos hereditariamente e são responsáveis por regular a sensibilidade à testosterona em fetos (RICE et al., 2012). Segundo os autores, o modelo que retrata a forma com que os genes são expressos pode explicar a alta prevalência da homossexualidade na população humana, de modo que se possa descartar a hipótese de que haja uma variação genética negativa no indivíduo homossexual a ser removida pela seleção natural. Essa teoria vai de encontro à hipótese anterior em que a orientação homossexual é definida parcialmente por um componente hereditário (KIRK et al., 2000; LÅNGSTRÖM et al., 2010; BURRI et al., 2011).

De acordo com o modelo, ao longo da gestação, tanto os fetos masculinos quanto os femininos são expostos a quantidades variadas do hormônio testosterona (RICE et al., 2012). A epimarca torna o cérebro dos meninos mais sensíveis à testosterona quando os níveis estão abaixo do normal a fim de preservar características masculinas e podendo, inclusive, influir na orientação sexual. O mesmo ocorre, mas inversamente, com as meninas. Quando a testosterona está acima do normal, a epimarca diminui sua sensibilidade ao hormônio. A partir desse modelo, a orientação homossexual é explicada pela transmissão de epimarcas sexualmente antagônicas, isto é, quando o pai transmite seus marcadores, que tiveram a função de torná-lo mais sensível à testosterona, para uma filha ou quando uma mãe passa para o filho, tornando-o menos sensível à testosterona (RICE et al., 2012).

No entanto, de acordo com outros especialistas que não estiveram envolvidos no estudo, mais análises são necessárias. "O estudo é interessante, mas a hipótese não foi testada. Precisamos de mais evidências, mas seria interessante entender como as epimarcas contribuem para a expressão da orientação sexual nos seres humanos", afirma o biólogo evolucionista da Universidade de St Andrews, na Escócia (ABBASI, 2012). 


\section{Componentes Genéticos: Polimorfismo Genético}

Acredita-se que a genética está envolvida na construção da orientação homossexual. Assim sendo sugere-se que, se um indivíduo possui um traço que reduz a sua reprodução sexual, este traço será selecionado negativamente, embora possa reaparecer por uma nova mutação (FORASTIERI, 2006; CAMPERIO-CIANI et al., 2008). Porém, o índice elevado da homossexualidade, entre $3-20 \%$ em homens e $2-9 \%$ em mulheres, nas diversas regiões geográficas do planeta mostra não ser plausível que esta frequência seja reflexo de mutações aleatórias (FORASTIERI, 2006; CÁCERES et al., 2006; SELL et al., 1995).

Sabe-se que nem todas as predisposições genéticas são totalmente expressas. Assim sendo, no ano de 2000, o psicólogo evolucionista norte-americano Edward Miller propôs que a homossexualidade masculina tem sobrevivido por meio de um polimorfismo equilibrado (MILLER, 2000). Segundo o pesquisador, os alelos impedem a androgenização parcial em fetos do sexo masculino durante a gravidez e isso poderia estar associado a uma orientação homossexual. Para o autor, por exemplo, seria possível feminilizar parcialmente o cérebro masculino através da heterozigoze em alguns locos gênicos: se apenas um alelo é alterado, um homem se tornaria mais apegado às crianças e ainda ser heterossexual, se ambos os alelos são alterados, ele também se tornaria feminilizado em sua orientação sexual.

No entanto, o modelo do polimorfismo equilibrado se torna discutível ao abrir margem a questionamentos do tipo: estaria a homossexualidade masculina diretamente ligada ao apego a crianças? Estaria um homem feminilizado em sua orientação sexual destinado a ser gay? Em 2009, um estudo realizado na Finlândia não encontrou resultados estatisticamente significativos para apoiar a teoria proposta por Miller (SANTTILA et al., 2009).

Sabe-se que existem duas linhas de evidência de que a homossexualidade é influenciada por polimorfismos genéticos: (1) os estudos duplos indicam que existem componentes genéticos e ambientais que contribuem para a expressão do fenótipo homossexual (BAILEY et al., 1999; PILLARD, BAILEY, 1998; DAWOOD et al., 2000); e (2) a homossexualidade masculina parece ser herdada com mais frequência a partir da linhagem materna, o que sugere a existência de polimorfismo, efeitos hereditários maternos e/ou genes ligados ao polimorfismo de $\mathrm{X}$, o que influencia a homossexualidade masculina (CAMPERIO-CIANI et al., 2004; PATTATUCCI, 1998).

Três mecanismos biológicos para a manutenção do polimorfismo genético causador da homossexualidade têm sido mais frequentemente mencionados na literatura biológica evolutiva: sobredominância, seleção dependente da frequência através de altruísmo familiar e seleção sexual antagônica. O primeiro mecanismo mostra que os genes que induzem à homossexualidade fornecem aptidão superior em condições heterozigóticas (MILLER, 2000). Um exemplo são os homens heterozigotos para um gene homossexual que podem ter maior sucesso em atrair mulheres e/ou seu esperma pode ter uma vantagem competitiva em relação ao de outros homens. 
O segundo mecanismo, que diz respeito ao altruísmo familiar, indica que os homossexuais ajudam os seus parentes próximos, aumentando assim, inclusive, a sua própria aptidão sexual (PILLARD e BAILEY, 1998). O terceiro mecanismo que foi brevemente mencionado na década de 90 (PILLARD, BAILEY, 1998; HAMMER, COPELAND, 1994; MCKNIGHT, 1997), mas nunca foi rigorosamente explorado anteriormente, é o da seleção sexual antagônica em que alelos que diminuem a aptidão de um sexo são mantidos na população, pois aumentam a aptidão do outro sexo (ARNQVIST, 2005). A importância potencial deste mecanismo é destacada por dados recentes publicados nos Estados Unidos e na Inglaterra que indicam que os parentes tanto da linhagem materna quanto da paterna de homossexuais masculinos têm a sua fecundidade aumentada (GAVRILETS, RICE, 2006; CAMPERIO-CIANI et al., 2004; KING et al., 2005).

Em suma, sabe-se que a homossexualidade é uma ocorrência comum em seres humanos (GAVRILETS e RICE, 2006). Estudos apresentam a homossexualidade como decorrente de hereditariedade em humanos entre $30-45 \%$, de modo que se supõe alguma predisposição genética, mas sua base genética e evolucionária ainda é mal compreendida (GAVRILETS, RICE, 2006; BAILEY et al., 1999).

\section{Componentes Genéticos: Padrão de Herança Ligada ao Cromossomo X}

Em 1993, a pesquisa norte-americana de Dean Hamer ficou conhecida como a descoberta do gene gay (HAMER et al., 1993). O estudo publicado por Hamer e colaboradores na prestigiada revista Science trouxe os resultados da análise de 114 famílias de homens homossexuais. Os autores afirmavam com 99,5\% de certeza haver encontrado indícios da existência de um ou mais genes ligados à orientação sexual na região q28 do cromossomo X (ou Xq28).

O método de estudo empregado por Hamer e sua equipe consistiu em uma análise de pedigree (estudos de famílias), seguida por estudos moleculares das famílias que tivessem pelo menos um par de irmãos homossexuais e nas quais o padrão de distribuição da homossexualidade nas árvores genealógicas coincidisse com o padrão de herança ligada ao cromossomo X (HAMER et al., 1993). Os resultados do estudo indicaram, em suma, que a maior parte dos homossexuais se concentrava no lado materno das famílias, o que sugeria uma herança ligada ao cromossomo $\mathrm{X}$.

Das famílias nas quais a análise de heredogramas sugeriu uma possível transmissão materna dos possíveis genes que contribuiriam para a orientação homossexual, foram convocados 40 pares de irmãos homossexuais para estudos moleculares (HAMER et al., 1993). Os dados obtidos pelas técnicas de biologia molecular sugeriram uma correlação entre a homossexualidade nessas famílias e marcadores na região q28, uma região de aproximadamente 4 milhões de pares de bases no braço longo do cromossomo X. Um estudo de revisão publicado nos Estados Unidos em 1998 encontrou resultados semelhantes aos de Hamer e sua equipe, 
porém, não observou correlação entre marcadores na região Xq28 e a homossexualidade feminina (PATTATUCCI, 1998).

Embora o estudo realizado por Hamer e colaboradores seja o trabalho mais significativo sobre causas relacionadas à orientação sexual no campo da genética molecular, anos mais tarde sua teoria foi questionada devido às várias lacunas metodológicas (MCKNIGHT, 1997). Uma das críticas ao trabalho de Hamer aponta para o não estudo da região Xq28 dos irmãos heterossexuais dos homossexuais analisados, deixando de lado a possibilidade de que os irmãos heterossexuais também compartilhassem com seus irmãos homossexuais os mesmos marcadores na região Xq28 (PATTATUCCI, 1998). Além disso, Neil Risch, um dos criadores dos métodos estatísticos usados por Hamer e sua equipe, questionou a significância estatística dos resultados obtidos (BYNE, 1994).

Outra limitação do estudo é a que se refere à análise exclusiva de famílias com pelo menos dois irmãos homossexuais (logo, estão exclusos homossexuais que são filhos únicos), além de a metodologia não permitir estudar os homossexuais que, nos estudos de família, aparecem do lado paterno (PATTATUCCI, 1998). A pesquisadora Mary-Claire King do Departamento de Biologia Celular e Molecular da Universidade da Califórnia relata que também houve limitações relacionadas a estudos de história familiar e pesquisas com dados sobre ligação genética, pois estes não podem estimar a magnitude da influência genética sobre um traço em uma população (KING, 1993). Ademais, as análises moleculares foram selecionadas de maneira enviesada para a pesquisa, o que dificulta a generalização das conclusões obtidas (KING, 1993).

Contrariando ainda mais a hipótese de Hamer, em 1999 uma pesquisa publicada na revista Science, do canadense George Rice e colaboradores (RICE et al., 1999), examinou amostras genéticas de 52 duplas de irmãos gays e disse não ter encontrado sinais de que algum gene do Xq28 pudesse desempenhar qualquer papel relevante na orientação sexual.

Em 2005, foi publicado nos Estados Unidos o primeiro estudo de biologia molecular com busca ampla no genoma humano de genes candidatos para a homossexualidade (MUSTANSKI et al., 2005). Foram analisados 456 indivíduos não provenientes de 146 famílias não relacionadas, com dois ou mais irmãos homossexuais e utilizaram-se 403 marcadores microssatélites, a intervalos de $10 \mathrm{cM}$. Nesse estudo, foram encontrados três picos de ligação nominalmente significativos, indicando três locos gênicos nos cromossomos 7 (região 7q36), 8 (região 8p12) e 10 (região 10q26) com vários genes candidatos de interesse que, possivelmente, podem determinar a orientação homossexual masculina, bem como dar um suporte limitado para o relato prévio de ligação ao loco do cromossomo X (Xq28) (SWAAB, HOFMAN, 1990; LALUMIÈRE et al., 2000; MUSTANSKI et al., 2005).

Contudo, os autores dessa pesquisa assinalam algumas limitações inerentes à mesma; entre outras, a resolução média de $10 \mathrm{cM}$ pode ter subestimado os valores de contagem das estimativas de probabilidade; o estudo não incluiu mulheres, pois ainda não está claro se a orientação sexual feminina está determinada pelos mesmos fatores que a masculina 
(MUSTANSKI et al., 2005). Ademais, segundo os autores, o próximo passo a este estudo é realizar uma busca nas regiões de interesse usando um maior número de marcadores e uma maior resolução.

\section{Componentes Genéticos: Gêmeos Univitelinos}

Numerosos estudos que investigam a orientação sexual humana demonstraram que a homossexualidade masculina e a feminina parece ser familiar (BAILEY et al., 2000; KENDLER et al., 2000; LÅNGSTRÖM et al., 2010). Estudos feitos com irmãos gêmeos e adotivos sugerem que a orientação homossexual se deve principalmente à genética quando comparada às influências ambientais compartilhadas, com genes correspondendo possivelmente a pelo menos metade da variação na orientação sexual (LÅNGSTRÖM et al., 2010; PILLARD, BAILEY, 1998). No entanto, diferentes etiologias têm sido propostas para a orientação homossexual masculina e a feminina, indicando que, se fatores genéticos contribuem para a homossexualidade, eles poderiam variar entre machos e fêmeas (KIRK et al., 2000).

Evidências a favor da contribuição de componentes genéticos para a orientação homossexual vêm de estudos que comparam as concordâncias para o traço entre os gêmeos idênticos (monozigóticos ou univitelinos), os nãos idênticos (dizigóticos ou bivitelinos), os irmãos não gêmeos e irmãos adotados (BAILEY, PILLARD, 1991; BAILEY et al., 1993; PILLARD, BAILEY, 1998).

Os primeiros estudos de taxas de concordância mostraram que a contribuição genética pode ser bastante significativa; para homens, $52 \%$ dos gêmeos monozigóticos, $22 \%$ dos gêmeos dizigóticos e 11\% dos irmãos não gêmeos dos homossexuais eram também homossexuais, enquanto que, para mulheres, $48 \%$ das gêmeas monozigóticas, $16 \%$ das dizigóticas e $6 \%$ das irmãs não gêmeas de homossexuais eram também homossexuais (BAILEY, PILLARD, 1991; BAILEY et al., 1993; PILLARD, BAILEY, 1998). Para os autores, no entanto, pode ter havido possíveis vieses de seleção. Por exemplo, alguns indivíduos podem ter se voluntariado, porque eles sabiam que tinham gêmeos que também tinham orientação homossexual (PILLARD, BAILEY, 1998).

Em 2007, o pesquisador Francis Collins, que lidera o Projeto Genoma Humano, estimou que a herdabilidade da homossexualidade fica em torno de $20 \%$ (COLLINS, 2007). Em contraste com esses dados, um estudo prévio de coorte realizado na Austrália com 4901 gêmeos australianos indicou uma estimativa de herdabilidade variando entre 50 e $60 \%$ em mulheres e aproximadamente 30\% em homens (KIRK et al., 2000).

Em 2008, um estudo realizado na Finlândia analisou 6001 mulheres homossexuais e 3152 homens homossexuais, entre 18 e 33 anos de idade, por meio de questionário, abordando questões relacionadas à frequência de contato sexual com pessoas do mesmo sexo e à probabilidade de aceitarem relação sexual com uma pessoa atraente do mesmo sexo (SANTTILA 
et al., 2008). Dentre os achados do estudo, está a frequência de gêmeos inclinados a serem homossexuais (32,8\% dos homens e $65,4 \%$ das mulheres); gêmeos monozigóticos foram duas vezes mais propensos a responderem da mesma forma; além da observação de que os genes têm um papel na determinação da orientação homossexual.

\section{Componentes Genéticos: Seleção Sexual Antagônica}

Em 2008, em entrevista concedida pelo geneticista comportamental italiano Andrea Ciani, o pesquisador afirma que a homossexualidade faz parte da natureza (CAMPERIO-CIANI, 2008). Para o autor, a teoria que ele e sua equipe desenvolveram indica que a orientação homossexual masculina tem um componente genético herdado das mães, e os genes por trás dele são os mesmos que, em mulheres, estimulam a fertilidade.

Para tanto, eles seguiram quatro pré-requisitos empíricos. O primeiro é o de que a homossexualidade está presente em todas as populações humanas. O segundo é o de que não há nenhuma população em que a maioria das pessoas seja homossexual. O terceiro, por sua vez, mostra que a homossexualidade tende a seguir em famílias pela linhagem materna. Isso significa que se um indivíduo é homossexual, há uma probabilidade maior de o seu tio materno também ser homossexual. O quarto, identificado em 2004, é que mães e tias da linhagem materna de homossexuais costumam ter proles maiores (CAMPERIO-CIANI et al., 2004; CAMPERIO-CIANI, 2008).

Para o autor, existem muitos modelos para a difusão genética de características. Há aqueles que testam a difusão com um único loco gênico, outros com mais locos (CAMPERIOCIANI, 2008). Em 2008, uma pesquisa realizada na Itália por meio de análise matemática sistemática testou diversos estudos envolvendo modelos com dois locos, porém quase todos falharam, exceto um, o modelo da 'seleção sexual antagônica', baseado em dois locos gênicos em dois diferentes cromossomos (CAMPERIO-CIANI et al., 2008). Um no cromossomo X - que os homens recebem apenas de suas mães -, e o outro nos cromossomos não sexuais. Para os autores, somente esse modelo explica todos os pré-requisitos que encontraram. Ademais, ele mostra características peculiares que dão uma vantagem reprodutiva para um sexo e desvantagem para outro (CAMPERIO-CIANI et al., 2008).

\section{CONCLUSÕES}

Pode-se observar que foram muitas as evidências científicas encontradas ao longo do tempo para explicar alguns dos componentes biológicos e genéticos da homossexualidade, principalmente em indivíduos do sexo masculino. No entanto, ainda hoje, não há uma explicação definitiva sobre quais seriam os componentes determinantes da orientação homossexual. $\mathrm{Na}$ teoria da ordem de nascimento fraternal, a pesquisa de meta-análise realizada por Blanchard em 
2004 apresentou a mais alta proporção de homossexuais (até 30\%) que podem atribuir a sua homossexualidade ao efeito de ordem de nascimento fraternal; isto o torna, sem dúvida, o estudo com a maior evidência epidemiológica de associação entre a ordem de nascimento fraternal e a orientação homossexual.

Ainda em relação à mesma teoria, embora a pesquisa de Bogaert em 2006 tenha descoberto que a relação entre o número de irmãos mais velhos e a homossexualidade exista numa proporção maior no caso dos filhos que têm a mesma mãe, tal teoria apresentou algumas limitações. A saber, a maior parte dos casos de homossexuais não pode ser explicada por esse fenômeno e não se encaixa nesse modelo, pois faltam evidências experimentais para essa explicação; ela também não explica porque os anticorpos, ainda não detectados, não afetariam os caracteres sexuais primários, ou porque não existem na maior parte dos irmãos mais novos, isto é, a taxa de homossexualidade entre os meninos é cerca de $3 \%$, mas pode aumentar para $5 \%$ nas famílias com irmãos mais velhos, o que significa que os $95 \%$ restantes dos irmãos mais novos são heterossexuais.

A teoria da ativação cerebral por ferormônios, proposta por pesquisadores suecos em 2005, também apresentou fortes evidências de que nos cérebros de homens e mulheres homossexuais há, consequentemente, regiões ativadas em resposta aos derivados da testosterona e do estrógeno, que apresentam propriedades similares às dos feromônios. No entanto, mais estudos são necessários, pois a relação de causa e efeito não foi estabelecida na pesquisa.

A teoria da hereditariedade epigenética formulada em 2012 foi a primeira a inserir o conceito da transmissibilidade epigenética no contexto de desenvolvimento sexual. Acreditava-se que os traços da epigenética não eram hereditários, sendo apagados e recriados a cada passagem de geração. Ainda que o modelo não tenha provado que a epimarca é hereditária, devido à falta de testes específicos, ele contribui para a melhor compreensão dos componentes biológicos envolvidos, traz uma explicação lógica para o porquê de a homossexualidade ser algo tão frequente e reforça uma ideia cada vez mais prevalente: a de que a epigenética tem influência sobre a orientação sexual.

De acordo com a teoria do polimorfismo genético, a hipótese proposta por Miller percorre um caminho generalista inadequado. Embora seja a explicação de uma pesquisa dada pelo autor, reforça concepções provenientes do senso comum. Isto pode ser percebido tanto pelos questionamentos que surgem a partir deste discurso quanto pela falta de estudos que suportem, de forma fidedigna, a teoria.

$\mathrm{Na}$ teoria da herança ligada ao cromossomo $\mathrm{X}$, o ligamento com a região Xq28 reportada por Hamer e colaboradores em 1993 não se confirmou em estudos posteriores. Já a pesquisa de Mustanski e colaboradores em 2005 foi o primeiro estudo a realizar busca ampla no genoma, o qual mostrou valores significativos de ligamento nas regiões 7q36, 8p12 y 10q26, que devem ser 
estudadas com maior resolução, ou seja, estes resultados iniciais são preliminares e necessitam de confirmação de mais estudos genéticos.

No que diz respeito à teoria de gêmeos univitelinos, observou-se que o modelo proposto por Santtila e colaboradores em 2008 possui algumas limitações; baseando-se na aplicação de questionário, ele não deu oportunidade para explicação dos 'porquês', não localizou os genes responsáveis, a variável 'contato sexual' não foi definida, não houve grupo-controle e a relação de causa e efeito não foi estabelecida.

\section{REFERÊNCIAS}

ABBASI, J.. Could scientists have found a gay switch? Epigenetic molecules that regulate genes may influence homosexuality. Popular Science: New Technology, Science News, The Future Now, 2012. Disponível em: http://www.popsci.com/science/article/2012-12/being-born-gay-isnt-your-genes-its-them. Acesso: 10 fev 2013.

AMERICAN PSYCHOLOGICAL ASSOCIATION.. Sexual orientation and homosexuality. Washington, 2008. Disponível em: http://www.apa.org/helpcenter/sexual-orientation.aspx. Acesso: 18 dez. 2012.

ARNQVIST, G.; ROWE, L.. Sexual conflict. Nova Jersey: Princeton University Press, 2005.

BAILEY, J. M.; DUNNE, M. P.; MARTIN, N. G.. Genetic and environmental influences on sexual orientation and its correlates in an Australian twin sample. Journal of Personality and Social Psychology, Washington, v.78, n.3, p.524-536, 2000.

BAILEY, J. M.; PILLARD, R. C.. A genetic study of male sexual orientation. Archives of General Psychiatry, Chicago, v.48, n.12, p.1089-1096, 1991.

http://dx.doi.org/10.1001/archpsyc.1991.01810360053008.

BAILEY, J. M.; PILLARD, R. C.; NEALE, M. C.; AGYEI, Y.. Heritable factors influence sexual orientation in women. Archives of General Psychiatry, Chicago, v.50, n.3, p.217-223, 1993. DOI: http://dx.doi.org/10.1001/archpsyc.1993.01820150067007.

BAILEY, J. M.; PILLARD, R. C.; DAWOOD, K.; MILLER, M. B.; FARRER, L. A.; TRIVEDI, S.; MURPHY, R. L.. A family history study of male sexual orientation using three independent samples. Behavior Genetics, New York, v.29, n.2, p.79-86, 1999. DOI: http://dx.doi.org/10.1023/A:1021652204405.

BLANCHARD, R.; BOGAERT, A. F.. Additive effects of older brothers and homosexual brothers in the prediction of marriage and cohabitation. Behavior Genetics, New York, v.27, n.1, p.45-54, 1997. DOI: http://dx.doi.org/10.1023/A:1025663325313.

BLANCHARD, R.; BOGAERT, A. F.. Homosexuality in men and number of older brothers. The American Journal of Psychiatry, Arlington, v.153, n.1, p.27-31, 1996.

BLANCHARD, R.; ELLIS, L.. Birth weight, sexual orientation and the sex of preceding siblings. Journal of Biosocial Science, Cambridge, v.33, n.3, p.451-467, 2001. DOI: http://dx.doi.org/DOl:10.1017/S0021932001004515.

BLANCHARD, R.; KLASSEN, P.. H-Y antigen and homosexuality in men. Journal of Theoretical Biology, London, v.185, n.3, p.373-378, 1997. DOI: http://dx.doi.org/10.1006/jtbi.1996.0315.

BLANCHARD, R.. Fraternal birth order and the maternal immune hypothesis of male homosexuality. Hormones and Behavior, New York, v.40, n.2, p.105-114, 2001. DOI:

http://dx.doi.org/10.1006/hbeh.2001.1681.

BLANCHARD, R.. Quantitative and theoretical analyses of the relation between older brothers and homosexuality in men. Journal of Theoretical Biology, London, v.230, n.2, p.173-187, 2004. DOI: http://dx.doi.org/10.1016/i.jtbi.2004.04.021. 
BOCKLANDT, S.; HORVATH, S.; VILAIN, E.; HAMER, D. H.. Extreme skewing of $X$ chromosome inactivation in mothers of homosexual men. Human Genetics, New York, v.118, n.6, p.691-694, 2006. DOI: http://dx.doi.org/10.1007/s00439-005-0119-4.

BOGAERT, A. F.. Number of older brothers and sexual orientation: new tests and the attraction/behavior distinction in two national probability samples. Journal of Personality and Social Psychology, Washington, v.84, n.3, p.644-652, 2003. DOI: http://dx.doi.org/10.1037/0022-3514.84.3.644.

BOGAERT, A. F.. Biological versus nonbiological older brothers and men's sexual orientation. Proceedings of the National Academy of Sciences, Washington, v.103, n.28, p.10771-10774, 2006. DOI: http://dx.doi.org/10.1073/pnas.0511152103.

BURRI, A.; CHERKAS, L.; SPECTOR, T.; RAHMAN, Q.. Genetic and environmental influences on female sexual orientation, childhood gender typicality and adult gender identity. PLoS One, San Francisco, v.6, n.7, p.e21982, 2011. DOI: http://dx.doi.org/10.1371/journal.pone.0021982.

BYNE, W.. The biological evidence challenged. Scientific American, New York, v. 270, n. 5, p. 50-55, 1994.

CÁCERES, C.; KONDA, K.; PECHENY, M.; CHATTERJEE, A.; LYERLA, R.. Estimating the number of men who have sex with men in low and middle income countries. Sexually Transmitted Infections, London, v.82, Suplemento 3, p.iii3-iii9, 2006.

CAMPERIO-CIANI, A.; CERMELLI, P.; ZANZOTTO, G.. Sexually Antagonistic Selection in human male homosexuality. PLoS One, San Francisco, v.3, n.6, p.e2282, 2008. DOI:

http://dx.doi.org/10.1371/journal.pone.0002282.

CAMPERIO-CIANI, A.; CORNA, F.; CAPILUPPI, C.. Evidence for maternally inherited factors favouring male homosexuality and promoting female fecundity. Proceedings of the Royal Society B: Biological

Sciences, London, v.271, n.1554, p.2217-2221, 2004. DOI: http://dx.doi.org/10.1098/rspb.2004.2872.

CAMPERIO-CIANI, A.. O homossexualismo não vai contra a natureza. Folha de São Paulo, São Paulo, jun. 2008. Disponível em: http://www1.folha.uol.com.br/fsp/ciencia/fe2106200801.htm. Acesso: 18 dez 2012.

COLLINS, F. S.. The Language of God: a scientist presents evidence for belief. New York: Free Press, 2007.

DAWOOD, K.; PILLARD, R. C.; HORVATH, C.; REVELLE, W.; BAILEY, J. M.. Familial aspects of male homosexuality. Archives of Sexual Behavior, New York, v.29, n.2, p.155-163, 2000. DOI: http://dx.doi.org/10.1023/A:1001955721992.

DESSUNTI, E. M.; SOUBHIA, Z.; ALVES, E.; ROSS, C.; SILVA, E. B.. Convivendo com a diversidade sexual: relato de experiência. Revista Brasileira de Enfermagem, Brasília, v.61, n.3, p.385-389, 2008. DOI: http://dx.doi.org/10.1590/S0034-71672008000300018.

FORASTIERI, V.. Orientações sexuais, evolução e genética. Revista Candombá, Salvador, v.2, n.1, p.5060, 2006.

FRIBERG, U.. Homossexualidade pode ser influenciada pela epigenética. Revista Veja, São Paulo, dez. 2012. Disponível em: http://veja.abril.com.br/noticia/ciencia/homossexualidade-pode-ser-influenciada-pelaepigenetica. Acesso: 20 dez 2012.

GAVRILETS, S.; RICE, W. R.. Genetic models of homosexuality: generating testable predictions.

Proceedings of the Royal Society B: Biological Sciences, London, v.273, n.1605, p.3031-3038, 2006. DOI: http://dx.doi.org/10.1098/rspb.2006.3684.

GREEN, R.. Birth order and ratio of brothers to sisters in transsexuals. Psychological Medicine, London, v.30, n.4, p.789-795, 2000.

HAMER, D. H.; HU, S.; MAGNUSON, V. L.; HU, N.; PATTATTUCII, A. M.. A linkage between DNA markers on the $X$ chromosome and male sexual orientation. Science, New York, v.261, n.5119, p.321-327, 1993.

DOI: http://dx.doi.org/10.1126/science.8332896. 
HAMER, D.; COPELAND, P.. The science of desire: the search for the gay gene and biology of behavior. New York: Simon \& Schuster, 1994.

KENDLER, K. S.; THORNTON, L.; GILMAN, S. E.; KESSLER, R. C.. Sexual Orientation in a U.S. national sample of twin and non twin sibling pairs. The American Journal of Psychiatry, Arlington, v.157, n.11, p.1843-1846, 2000. DOI: http://dx.doi.org/10.1176/appi.ajp.157.11.1843.

KING, M.; GREEN, J.; OSBORN, D. P. J.; ARKELL, J.; HETHERTON, J.; PEREIRA, E.. Family size in white gay and heterosexual men. Archives of Sexual Behavior, New York, v.34, n.1, p.117-122, 2005. DOI: http://dx.doi.org/10.1007/s10508-005-1006-8.

KING, M.. Sexual orientation and the X. Nature, London, v.364, n.6435, p.288-289, 1993.

KIRK, K. M.; BAILEY, J. M.; DUNNE, M. P.; MARTIN, N. G.. Measurement Models for Sexual Orientation in a Community Twin Sample. Behavior Genetics, New York, v.30, n.4, p.345-356, 2000.

LALUMIÈRE, M. L.; BLANCHARD, R.; ZUCKER, K. J.. Sexual orientation and handedness in men and women: a meta-analysis. Psychological Bulletin, Washington, v. 126, n. 4, p. 575-592, 2000. DOI: http://dx.doi.org/10.1037/0033-2909.126.4.575.

LÅNGSTRÖM, N.; RAHMAN, Q.; CARLSTRÖM, E.; LICHTENSTEIN, P.. Genetic and environmental effects on same-sex sexual behavior: a population study of twins in Sweden. Archives of Sexual Behavior, New York, v.39, n.1, p.75-80, 2010. DOI: http://dx.doi.org/10.1007/s10508-008-9386-1.

LEVAY, S.. A difference in hypothalamic structure between heterosexual and homosexual men. Science, New York, v.253, n.5023, p.1034-1037, 1991. DOI: http://dx.doi.org/10.1126/science.1887219.

MANNING, J. T.; SCUTT, D.; WILSON, J.; LEWIS-JONES, D. I.. The ratio of 2nd to 4th digit length: a predictor of sperm numbers and levels of testosterone, LH and oestrogen. Human Reproduction, Oxford, v.13, n.11, p. 3000-3004, 1998. DOI: http://dx.doi.org/10.1093/humrep/13.11.3000.

MANNING, J. T.; ROBINSON, S. J..2nd to 4th digit ratio and a universal mean for prenatal testosterone in homosexual men. Medical Hypotheses, New York, v.61, n.2, p.303-306, 2003. DOI:

http://dx.doi.org/10.1016/S0306-9877(03)00184-1.

MATIAS. D.. Psicologia e orientação sexual: realidades em transformação. Análise Psicológica, Lisboa, v.1, n.25, p.149-152, 2007.

MCKNIGHT, J.. Straight science? Homosexuality, evolution and adaptation. London: Routledge, 1997.

MILLER, E. M.. Homosexuality, birth order and evolution: toward an equilibrium reproductive economics of homosexuality. Archives of Sexual Behavior, New York, v.29, n.1, p.1-34, 2000. DOI: http://dx.doi.org/10.1023/A:1001836320541.

MURPHY, T. F.. Now what? The latest theory of homosexuality. APA Newsletter on Philosophy and Lesbian, Gay, Bisexual and Transgender Issues, Newark, n.1, p.120-123, 2000.

MUSTANSKI, B. S.; DUPREE, M. G.; NIEVERGELT, C. M.; BOCKLANDT, S.; SCHORK, N. J.; HAMER, D. H.. A genomewide scan of male sexual orientation. Human Genetics, New York, v.116, n.4, p.272-278, 2005. DOI: http://dx.doi.org/10.1007/s00439-004-1241-4.

PALMA, Y. A.; LEVANDOWSKI, D. C.. Vivências pessoais e familiares de homossexuais femininas. Psicologia em Estudo, Maringá, v.13, n.4, p.771-779, 2008. DOI: http://dx.doi.org/10.1590/S1413-73722008000400015.

PATTATUCCI, A.. Molecular investigation into complex behavior: lessons from sexual orientation studies. Human Biology, Detroit, v.70, n.2, p.367-386, 1998.

PILLARD, R. C.; BAILEY, J. M.. Human sexual orientation has a heritable component. Human Biology, Detroit, v.70, n.2, p.347-365, 1998. 
RICE, G.; ANDERSON, C.; RISCH, N.; EBERS, G.. Male homosexuality: absence of linkage to microsatellite markers at Xq28. Science, New York, v.284, n.5414, p.665-667, 1999. DOI:

http://dx.doi.org/10.1126/science.284.5414.665.

RICE, W. R.; FRIBERG, U.; GAVRILETS, S.. Homosexuality as a consequence of epigenetically canalized sexual development. The Quarterly Review of Biology, Baltimore, v.87, n.4, p.343-368, 2012. DOI: http://dx.doi.org/10.1086/668167.

ROBINSON, S. J.; MANNING, J. T.. The ratio of 2nd to 4th digit length and male homosexuality. Evolution and Human Behavior, Liverpool, v.21, n.5, p.333-345, 2000. DOI: http://dx.doi.org/10.1016/S1090$\underline{5138(00) 00052-0}$.

ROSARIO, V. A.. Homosexuality and Science: a guide to the debates. Santa Barbara: ABC-CLIO, 2002.

ROUGHGARDEN, J.. Evolution's Rainbow: diversity, gender, and sexuality in nature and people. Los Angeles: University of California Press, 2004.

SANTTILA, P.; SANDNABBA, N. K.; HARLAAR, N.; VARJONEN, M.; ALANKO, K.; von der PAHLEN, B.. Potential for homosexual response is prevalent and genetic. Biological Psychology, Amsterdam, v.77, n.1, p. 102-105, 2008. DOI: http://dx.doi.org/10.1016/j.biopsycho.2007.08.006.

SANTTILA, P.; HÖGBACKA, A. L.; JERN, P.; JOHANSSON, A.; VARJONEN, M.; WITTING, K.; PAHLEN, B.; SANDNABBA, K.. Testing Miller's theory of alleles preventing androgenization as an evolutionary explanation for the genetic predisposition for male homosexuality. Evolution and Human Behavior, New York, v.30, n.1, p.58-65, 2009. DOI: http://dx.doi.org/10.1016/j.evolhumbehav.2008.08.004.

SAVIC, I.; BERGLUND, H.; LINDSTROM, P.. Brain response to putative pheromones in homosexual men. Proceedings of the National Academy of Sciences, Washington, v.102, n.20, p.7356-7361, 2005. DOI: http://dx.doi.org/10.1073/pnas.0407998102.

SELL, R. L.; WELLS, J. A.; WYPIJ, D.. The prevalence of homosexual behavior and attraction in the United States, the United Kingdom and France: results of national population-based samples. Archives of Sexual Behavior, New York, v.24, n.3, p.235-248, 1995. DOI: http://dx.doi.org/10.1007/BF01541598.

SLATKIN, M.. Epigenetic inheritance and the missing heritability problem. Genetics, Austin, v.182, n.3, p.845-850, 2009. DOI: http://dx.doi.org/10.1534/genetics.109.102798.

SWAAB, D. F.; HOFMAN, M. A.. An enlarged suprachiasmatic nucleus in homosexual men. Brain Research, Amsterdam, v.537, n.1, p.141-148, 1990. DOI: http://dx.doi.org/10.1016/0006-8993(90)90350-K.

WILLIAMS, T. J.; PEPITONE, M. E.; CHRISTENSEN, S. E.; COOKE, B. M.; HUBERMAN, A. D.; BREEDLOVE, N. J.; BREEDLOVE, T. J.; JORDAN, C. L.; BREEDLOVE, S. M.. Finger-length ratios and sexual orientation. Nature, London, v.404, n.6777, p.455-456, 2000. DOI:

http://dx.doi.org/10.1038/35006555.

WOLFFE, A. P.; GUSCHIN, D.. Chromatin structural features and targets that regulate transcription. Journal of Structural Biology, San Diego, v.129, n.2, p.102-122, 2000. DOI:

http://dx.doi.org/10.1006/jsbi.2000.4217. 